\title{
GAMBARAN AKSES VIDEO PORNOGRAFI PADA REMAJA DI SMP NEGERI 9 PEKANBARU
}

\author{
Tia Arieska ${ }^{1}$, Siska Mayang Sari ${ }^{2}$, Yecy Anggreny ${ }^{3}$ \\ ${ }^{1,2,3}$ Program Studi Ilmu Keperawatan STIKes Hang Tuah Pekanbaru Jalan Mustafa Sari No. 5 Tangkerang Selatan \\ Pekanbaru, Riau - 28000. \\ Telepon: 085265648539, E-mail: Tiaarieska20@gmail.com
}

\begin{abstract}
ABSTRAK
Pada masa pubertas remaja mudah terpengaruh pada lingkungan yang buruk. Adanya teknologi di masa sekarang ini dikembangkan untuk tujuan yang positif, namun terkadang dalam hal ini remaja tersebut menggunakannya ke arah yang negatif, salah satunya adalah akses pornografi. Penelitian ini bertujuan untuk mengetahui gambaran akses video pornografi pada remaja. Jenis penelitian ini adalah deskriptif kuantitatif dengan jumlah sampel 258 remaja kelas VII dan VIII di SMP Negeri 9 Pekanbaru yang diambil menggunakan teknik stratified random sampling. Hasil penelitian didapatkan nilai tengah usia remaja adalah 13 tahun. Jenis kelamin mayoritas adalah laki-laki dengan jumlah 142 (53.0\%) responden. Alat untuk akses video pornografi sebagian besar menggunakan smartphone yaitu 241 (58.9\%) responden. Durasi remaja saat akses video pornografi terdapat nilai tengah yaitu 5 menit/akses dan nilai tengah frekuensi yaitu 5 kali/bulan. Lokasi saat askes video pornografi sebagian besar remaja memilih di rumah dengan jumlah 206 (55.0\%) responden. Dari penelitian yang dilakukan dapat disimpulkan bahwa banyaknya akses video pornografi dikalangan remaja. Diharapkan agar orang tua dapat lebih memantau anaknya agar tidak terjerumus ke arah yang negatif.
\end{abstract}

Kata kunci: Akses Video, Pornografi, Remaja

\begin{abstract}
In puberty adolescence are easily affected by bad environments. The existence of technology in the present time is developed for positive purposes, but sometimes in this caseadolescents use it in a negative purposes, one of them is access to pornography. The aim of this study is to determine the description of pornographic videos access of adolescents. This type of research was quantitative descriptive with a sample of 258 adolescents in class VII and VIII in SMPN 9 Pekanbaru taken using the stratified random sampling technique. The results of the study showed that the middle value of adolescence was 13 years. The majority of the sexes were men with a total of $142(53.0 \%)$ respondents. The tools for accessing pornographic videos mostly used smartphones, amountedto 241 (58.9\%) respondents. The duration of adolescents when accessing pornographic videos had a middle value of 5 minutes / accessand a mid-frequency value of 5 times / month. The location at the time of access to pornographic video smost of the adolescents choosed at home with a total of 206 (55.0\%) respondents. From the research conducted it can be concluded that there are many pornographic video access among adolescents. It is expected that parents can better monitor their children so they do not fall into a negative direction.
\end{abstract}

Keywords: video access, pornographic, adolescents

\section{PENDAHULUAN}

Masa remaja merupakan masa yang paling penting dalam hidup kita. Pandangan meluas dan sering timbul ide-ide yang baru. Masa ini juga bersifat unik karena kita tumbuh menjadi lebih dewasa secara mental (Stoppard,
2010). Masa remaja dimulai sekitar umur 10-13 tahun dan akan berakhir 18-22 tahun. Masa remaja awal berlangsung dimasa sekolah menengah pertama dengan terjadi pubertas pada masa ini. Perubahan biologis, kognitif, dan sosio emosional yang dialami oleh remaja terjadi pada saat perkembangan fungsi seksual hingga proses 
Tia Arieska ${ }^{1}$, Siska Mayang Sari $^{2}$, Yecy Anggreny ${ }^{3}$,Gambaran Akses Video Pornografi pada Remaja di SMP Negeri 9 Pekanbaru

berpikir abstrak dan mengambil keputusan sendiri. Dimasa remaja awal, mulai berpikir secara egosentris, keinginan lebih banyak waktu bersama teman sebaya dengan percakapan yang lebih intim dan lebih membuka diri, serta minat terhadap relasi romantis (Santrock, 2007).

Remaja berusia 12-15 tahun memiliki kekuatan fisik yang luar biasa serta tumbuh keingintahuan dan keinginan untuk coba-coba pada dirinya (Sarwono, 2012). Pada masa ini juga kebanyakan ciri-ciri tingkah laku remaja sering mengarah ke arah yang negatif karena akan mengalami perasaan yang kurang senang, menentang lingkungan, mempunyai perasaan gelisah, dan mudah terpengaruh pada lingkungan yang buruk (Willis, 2007).

Perkembangan zaman yang semakin canggih, internet dapat mudah diakses bagi siapapun dikalangan masyarakat. Kemudahan yang diberikan dapat menimbulkan dampak positif dan negatif pada

masyarakat terutama generasi penerus bangsa. Adanya internet dapat memudahkan dalam mengakses berbagai informasi dari dunia luar (KPAI, 2015). Elektronik kecil yang memiliki fungsi dan selalu menyajikan teknologi terbaru merupakan perangkat dari Gadget. Dengan adanya teknologi di masa sekarang ini seperti internet, handphone, buku bacaan, VCD, TV, dan lain sebagainya dikembangkan untuk tujuan yang positif, namun terkadang pengguna teknologi tersebut menggunakan dengan hal-hal yang negatif, salah satunya adalah pornografi.
Menurut data yang didapatkan KPAI, sejak tahun 2011 sampai 2014, jumlah anak korban pornografi dan kejahatan online di Indonesia telah mencapai 1.022 anak. Anakanak yang menjadi korban pornografi online sebesar $28 \%$, pornografi, prostitusi anak online $20 \%$, objek VCD porno $15 \%$ dan anak korban kekerassan seksual online $11 \%$. Jumlah ini diperkirakan akan semakin meningkat jika tidak diatasi secara optimal. Pertumbuhan angka anak korban kejahatan online ini akan bertambah seiring meningkatnya jumlah pengguna internet di Indonesia (KPAI, 2015).

Hasil Riset Kantor Berita Associated Press (AP) pernah menempatkan Indonesia sebagai tempat pornografi nomer dua di dunia setelah Rusia. Adapun frekuensinya, 44,9\% remaja mengaku kurang dari 5 kali menonton, membaca situs porno, foto, video, majalah porno dalam satu bulannya, dan $15,2 \%$ ratarata 11-15 kali dalam satu bulannya (Asti, 2011). Dari Hasil penelitian yang dilakukan di SMP Negeri 9 Pekanbaru kepada 10 orang remaja SMP dengan 6 remaja laki-laki dan 4 remaja perempuan didapatkan remaja SMP semuanya memiliki gedget salah satunya smartphone dengan durasi pemakaian gadget 5-12 jam/hari. Remaja Putri mengaku menonton film korea yang berbau pornografi dengan durasi 1-2 jam/hari dan laki-laki menyebutkan hampir setiap harinya bermain video games yang berbau pornografi. Dari 10 remaja tersebut 9 diantaranya pernah akses video internet. Salah satunya akses konten 
pornografi. Dari 6 remaja laki-laki 4 orang yang mengaku terangsang setelah melihat video porno tersebut. Sedangkan remaja perempuan merasa biasa saja.

Berdasarkan latar belakang di atas, maka peneliti tertarik untuk mengetahui "Gambaran Akses Video Pornografi pada Remaja siswasiswi 9 Pekanbaru Kecamatan Tenayan Raya”.

\section{METODE PENELITIAN}

Jenis penelitian berupa kuantitatif dengan desain penelitian adalah deskriptif sederhana. Penelitian dilakukan di SMP Negeri 9 Pekanbaru Kecamatan Tenayan Raya Pekanbaru, dengan populasi seluruh siswa/siswi kelas VII Dan VIII yang berjumlah 726 orang remaja dan sampel 258 remaja.

Alat pengumpulan data menggunakan kuesioner.

\section{HASIL PENELITIAN}

\section{Analisis Univariat}

Tabel 1

Distribusi usia remaja SMP Negeri 9 Pekanbaru

\begin{tabular}{ccccc}
\hline Mean & Median & SD & Min & Max \\
\hline 13,24 & 13,00 & 0,952 & 12 & 15
\end{tabular}

Karakteristik usia dapat disimpulkan bahwa nilai tengah (median) responden berusia 13,00 tahun dengan usia terendah 12 tahun dan tertinggi 15 tahun.
Tabel 2

Distribusi frekuensi jenis kelamin remaja SMP Negeri 9 Pekanbaru

\begin{tabular}{clcc}
\hline No. & Jenis kelamin & $\begin{array}{c}\text { Frekuensi } \\
(f)\end{array}$ & $\begin{array}{c}\text { Persentase } \\
(\%)\end{array}$ \\
\hline 1 & Laki-laki & 142 & 53,0 \\
2 & Perempuan & 116 & 43,3 \\
\hline & Total & 258 & 96,3 \\
\hline & Dari hasil & distribusi & frekuensi
\end{tabular}

berdasarkan jenis kelamin mayoritas adalah laki-laki dengan jumlah 142 responden $(53,0 \%)$.

Tabel 3

Distribusi frekuensi alat akses video pornografi di SMP Negeri 9 Pekanbaru

\begin{tabular}{clcc}
\hline No & $\begin{array}{l}\text { Alat akses } \\
\text { video } \\
\text { pornografi }\end{array}$ & $\begin{array}{c}\text { Frekuensi } \\
(f)\end{array}$ & $\begin{array}{c}\text { Persentase } \\
(\%)\end{array}$ \\
\hline 1 & Smartphone & 241 & 58,9 \\
2 & Tablet & 47 & 11,4 \\
3 & Komputer & 48 & 11,7 \\
4 & Laptop & 74 & 18,0 \\
\hline & Total & 410 & 100 \\
\hline
\end{tabular}

Berdasarkan alat yang digunakan untuk akses video pornografi menunjukkan sebagian besar remaja menggunakan Smartphoneyaitu $241(58,9 \%)$ responden.

Tabel 4

Distribusi durasi akses video pornografi di SMP 9 Pekanbaru

\begin{tabular}{ccccc}
\hline Mean & Median & SD & Min & Max \\
\hline 8,61 & 5,00 & 8,118 & 1 & 60
\end{tabular}

Berdasarkan hasil penelitian durasi akses video pornografi terdapat nilai tengah 
Tia Arieska ${ }^{1}$, Siska Mayang Sari $^{2}$, Yecy Anggreny ${ }^{3}$,Gambaran Akses Video Pornografi pada Remaja di SMP Negeri 9 Pekanbaru

(median) yaitu 5,00 menit/akses dengan durasi paling cepat 1 menit/akses dan paling lama 60 menit/akses.

Tabel 5

Distribusi frekuensi akses video pornografi di SMP Negeri 9 Pekanbaru

\begin{tabular}{ccccc}
\hline Mean & Median & SD & Min & Max \\
\hline 5,76 & 5,00 & 3,930 & 1 & 25
\end{tabular}

Berdasarkan hasil penelitian frekuensi akses video pornografi terdapat nilai tengah (median) yaitu 5,00 kali/bulan dengan frekuensi saat akses paling sedikit $1 \mathrm{kali} / \mathrm{bulan}$ dan paling sering $25 \mathrm{kali} / \mathrm{bulan}$.

Tabel 6

Distribusi frekuensi lokasi akses video pornografi di SMP Negeri 9 Pekanbaru

\begin{tabular}{llcc}
\hline No & $\begin{array}{l}\text { Lokasi akses video } \\
\text { pornografi }\end{array}$ & $\begin{array}{c}\text { Frekuensi } \\
(f)\end{array}$ & $\begin{array}{c}\text { Persentase } \\
(\%)\end{array}$ \\
\hline 1 & Sekolah & 30 & 8,0 \\
2 & Warnet & 66 & 17,6 \\
3 & Rumah & 206 & 55,0 \\
4 & $\begin{array}{l}\text { Tempat } \\
\text { tongkrongan }\end{array}$ & 72 & 19,4 \\
\hline & Total & 374 & 100
\end{tabular}

Berdasarkan hasil penelitian lokasi saat askes video pornografi mayoritas remaja memilih di rumah dengan jumlah 206 (55,0 \%) responden.

\section{PEMBAHASAN}

\section{Analisis Univariat}

\section{Usia}

Hasil penelitian yang didapatkan oleh peneliti yaitu terdapat nilai tengah (median) responden berusia 13 tahun. Menurut Potter dan Perry (2009) remaja yang berusia 13 tahun termasuk pada remaja awal (Early adolescence), dimana pada fase ini remaja akan membandingkan dirinya dengan orang lain, sangat mudah dipengaruhi oleh teman sebaya dan lingkungan dan lebih senang bergaul dengan teman sejenis. Hasil penelitian yang dilakukan oleh Rumyemi, Evawani dan Nova (2013) juga menemukan bahwa responden yang berusia 13-14 tahun adalah responden terbanyak remaja yang ada di SMP Negeri 25 Pekanbaru.

Willis (2012) menjelaskan bahwa pada masa remaja memiliki tiga ciri utama pada masa pubertas yaitu ciri primer atau matangnya organ seksual yang ditandai dengan adanya menstruasi pertama pada anak perempuan dan produksi cairan sperma pada anak laki-laki. Pada masa ini juga sudah mulai di produksi hormon seks pada remaja baik laki-laki maupun perempuan. Dimana pada remaja laki-laki sudah memproduksi hormon testosteron dan pada perempuan yaitu hormon progesteron dan eksterogen yang menyebabkan remaja memiliki keinginan dalam hal-hal yang berbau seksual. Kemudian yang kedua yaitu ciri sekunder atau terjadinya perubahan bentuk tubuh pada kedua jenis 
kelamin dan ciri tersier atau perubahan yang terjadi pada tingkah laku. Perubahan ini juga berhubungan dengan perubahan psikis, yaitu perubahan tingkah laku yang tampak seperti perubahan minat belajar, keterkaitan terhadap lawan jenis dan menurunnya minat kerja. Pada masa ini remaja juga mudah terpengaruh dengan lingkungan yang buruk serta senang melakukan hal-hal yang baru.

Berdasarkan penjelasan diatas dapat disimpulkan bahwa lingkungan yang buruk akan mempengaruhi remaja terjerumus dengan hal-hal yang negatif. Teknologi yang canggih dimasa sekarang menyebabkan masyarakat mudah tergiur dengan hal-hal yang baru yang di fasilitasi oleh aplikasi di internet. Internet dapat berdampak positif dan negatif bagi penggunanya. Pada umumnya remaja memiliki rasa ingin tahu yang tinggi dan mempunyai tahap perkembangan yang sangat mudah terpengaruh dengan hal yang belum pernah diketahuinya. Situs-situs pornografi yang tersebar luas dan mudah di akses menimbulkan rasa keingintahuan pada remaja dan mencoba untuk melihat video yang berbau seksual tersebut.

\section{Jenis Kelamin}

Hasil penelitian yang dilakukan sebagian besar responden berjenis kelamin laki-laki yaitu sebanyak $142(53,0 \%)$ responden, dan $116(43,3 \%)$ responden perempuan. Hal ini sesuai yang dilakukan oleh penelitian Yutifa, Ari dan Misrawati (2015) di 6 SMA/Sederajat di Pekanbaru dengan jumlah 99 responden yang menyatakan bahwa sebagian besar responden yang terpapar pornografi melalui elektronik berjenis kelamin laki-laki yaitu sebanyak $57 \quad(57,6 \%)$ dan $42 \quad(42,4 \%)$ responden perempuan. Dari hasil analisis tersebut dapat dilihat bahwa lebih banyak responden laki-laki yang terpapar pornografi dibanding perempuan.

Menurut teori Santrock

(2007)

menjelaskan terdapat dua jenis hormon yang memiliki kadar kepekatan yang berbeda pada laki-laki dan perempuan, yaitu androgen jenis utama dari hormon seks laki-laki dan estrogen jenis utama dari hormon perempuan. Testosteron merupakan androgen yang berperan penting bagi perkembangan pubertas pada laki-laki. Selama masa pubertas, munculnya kadar testosteron berkaitan dengan jumlah perubahan fisik pada laki-laki, termasuk perkembangan genital eksternal, bertambahnya tinggi badan, dan perubahan suara. Kadar testosteron pada remaja laki-laki juga berkaitan dengan hasrat seksual dan aktivitas seksual. Identitas hormon yang berkontribusi terhadap hasrat seksual dan aktivitas pada remaja perempuan kurang terlihat jelas pada perempuan dibandingkan pada laki-laki. Pada laki-laki kadar testosteron meningkat 18 kali lipat namun hanya 2 kali lipat pada perempuan selama pubertas. Sehingga dapat disimpulkan bahwa laki-laki mempunyai hasrat seksual lebih tinggi dari pada perempuan sehingga laki-laki lebih aktif mencari informasi tentang pornografi yang 
Tia Arieska ${ }^{1}$, Siska Mayang Sari $^{2}$, Yecy Anggreny ${ }^{3}$,Gambaran Akses Video Pornografi pada Remaja di SMP Negeri 9 Pekanbaru

akan menimbulkan keinginan untuk mengakses konten atau video yang berbau pornografi.

\section{Alat akses video pornografi}

Penelitian yang dilakukan di SMP Negeri 9 Pekanbaru, alat yang digunakan untuk akses video pornografi menunjukkan bahwa pengguna smartphonelebih tinggi yaitu 241 pengguna $(58,9 \%)$. Hasil penelitian ini juga dijelaskan oleh peneliti Suwuh, Sefti dan Vandri (2017) bahwa penggunaan Smartphonedi SMA Negeri 2 Lawongan, menunjukkan bahwa dari 96 responden, terdapat $50(52,1 \%)$ responden yang memiliki penggunaan Smartphone yang tinggi dan akan mempengaruhi perilaku seksual pada remaja tersebut.

Asti (2011) menjelaskan perkembangan pornografi di Indonesia semakin melonjak dengan teknologi yang semakin canggih yaitu handphone yang memiliki berbagai fasilitas kamera, multimedia dan pemutar video. Menurut Sony yang dikutip Asti (2011) menyatakan bahwa semakin banyak video porno lokal yang di uploud ke internet, minimal 2 video/hari dengan handphone berkamera yang berisi adegan hubungan seks dalam durasi singkat.

Muflih, Hamzah dan Puniawan (2017) menyatakan bahwa smartphone bagi kalangan remaja digunakan tidak hanya untuk berkomunikasi tetapi juga untuk video call, berfoto, membuka internet, sarana hiburan dam sarana pembelajaran. Remaja saat ini banyak menyalahgunakan teknologi khususnya smartphone, misalnya membuka situs porno hingga lupa waktu karena permainan didalam smartphone yang akan membawa dampak buruk bagi remaja.

Berdasarkan uraian diatas dapat disimpulkan bahwa smartphone memberikan pengaruh yang besar pada remaja salah satunya remaja dapat menyimpan dan mengakses video pornografi kapanpun dan dimanapun tanpa adanya pengawasan dari orang tua.

\section{Durasi akses video pornografi pada remaja}

Hasil penelitian berdasarkan durasi akses video pornografi di SMP Negeri 9 Pekanbaru terdapat nilai tengah (median) yaitu 5 menit/akses. Penelitian yang dilakukan oleh Dursa (2017) menjelaskan bahwa dari 77 responden, menunjukkan dalam sehari durasi kurang dari 30 menit responden menonton paling banyak yaitu 53 responden $(68,8 \%)$.

Penelitian yang dilakukan oleh Anisah (2016) juga menyatakan bahwa dalam satu minggu jika materi pornografi dalam bentuk gambar tersimpan di media handphone bisa hampir setiap hari mereka lihat, durasi menonton tayangan tersebut kurang lebih 5-40 menit dan atensi dari tayangan yang mereka lihat menimbulkan pembelajaran dan peniruan dalam pergaulan dan gaya berpacaran mereka. Hal ini juga dijelaskan oleh peneliti Rumyeni, Evawani dan Nova (2013) bahwa banyak remaja yang menghabiskan waktu dengan 
melihat konten-konten pornografi, dimana remaja menghabiskan waktu untuk melihat konten tersebut dengan durasi lebih dari satu jam $(87,6 \%)$. Waktu yang dihabiskan untuk melihat, mendengar, dan membaca konten pornografi di media massa lebih banyak dibandingkan dengan aktivitas lainnya ketika mengakses konten media massa yaitu $(88,3 \%)$.

Hasil penelitian yang di lakukan oleh peneliti Muflih, Hamzah dan Puniawan (2017) menjelaskan terdapat durasi pengguna smartphoneandroid dengan lama pemakaian lebih dari 3 jam/hari (>3 jam/hari). Remaja menghabiskan waktu 2,5 jam/hari untuk browsinginternetdan bermain gameonline.

Penjelasan diatas dapat disimpulkan bahwa remaja yang melakukan browsing diinternet memiliki kemungkinan untuk melihat atau mencari sesuatu yang berbau pornografi. Hasil penelitian yang peneliti dapatkan terdapat durasi akses video pornografi pada remaja yaitu dengan nilai tengah 5 menit/akses. Remaja yang sudah terpapar dengan pornografi memiliki kemungkinan yang besar akan merasa ketagihan menonton video yang berbau pornografi. Dengan durasi yang semakin tinggi maka akan mempengaruhi tubuh dan pikiran seseorang serta akan membawa seseorang terhadap penggunaan waktu yang sia-sia sehingga akan berdampak buruk bagi remaja.

\section{Frekuensi akses video pornografi}

Hasil penelitian berdasarkan frekuensi akses video pornografi terdapat nilai tengah yaitu 5 kali/Bulan.Penelitian ini sejalan dengan peneliti Rumyeni, Evawani dan Nova (2013) bahwa dapat diketahui responden yang sering melihat, mendengar, dan membaca konten pornografi di media massa tinggi sebesar $76,6 \%$.

Data hasil Riset Kantor Berita Associated Press (AP) pernah menempatkan Indonesia sebagai tempat pornografi nomor dua di dunia setelah Rusia. Adapun frekuensinya yaitu $44,9 \%$ remaja mengaku kurang dari 5 kali menonton, membaca situs porno, foto, video, majalah porno dalam satu bulannya, dan $15,2 \%$ rata-rata $11-15$ kali dalam satu bulannya (Asti, 2011). Penelitian terkait diatas sejalan dengan hasil penelitian ini, dimana nilai tengah pada remaja yang mengakses video porno adalah sebanyak 5 kali/bulan serta remaja di SMP Negeri 9 Pekanbaru bisa dikatakan sudah terbiasa dalam mengakes video pornografi. Kebiasaan yang buruk ini sangat berpengaruh besar pada remaja sehingga akan meningkatkan minatnya terhadap seks.

Individu yang baru pertama kali melihat pornografi akan menimbulkan konflik dalam dirinya sehingga individu akan merasa bersalah. Namun jika kebiasaan itu dilakukan berulang-ulang maka individu merasa kecanduan pornografi merupakan hal yang wajar. Contohnya Individu yang baru pertama kali mengakses pornografi akan merasa takut, rasa bersalah, berdebar-debar namun karena 
Tia Arieska ${ }^{1}$, Siska Mayang Sari $^{2}$, Yecy Anggreny ${ }^{3}$,Gambaran Akses Video Pornografi pada Remaja di SMP Negeri 9 Pekanbaru

dibiasakan maka hal yang ditakuti akan hilang dan dianggap wajar (Djubaedah, 2009).

\section{Lokasi saat akses video pornografi}

Hasil penelitian untuk lokasi yang didapatkan saat mengaskes video pornografi, remaja lebih memilih di rumah sebagai tempat mereka membuka video yang terlarang tersebut dengan jumlah responden yang memilih sebesar 206 (55,0\%). Berdasarkan penelitian yang dilakukan oleh Saputri (2014) bahwa paling banyak responden menggunakan internet di warnet yaitu sebanyak 69 (48,9\%). Terbanyak kedua responden memilih di rumah sendiri sebanyak 48 (34\%). Hal ini disebabkan karena pada zaman yang canggih ini remaja lebih memlilih menggunakan Smartphone untuk mengakses internet di rumah dari pada harus mengeluarkan uang untuk pergi ke warnet. Dirumah remaja juga lebih merasa nyaman karena tidak diketahui orang banyak sehingga lebih leluasa untuk mengakses linklink video yang berbau pornografi.

Didukung oleh Elly, $\mathrm{R}$ yang dikutip dalam Nadesul (2011) menjelaskan bahwa lebih banyak anak yang melihat materi pornografi justru dirumahnya sendiri. (Jubille (2010) juga menjelaskan bahwa adanya Handphone dengan teknologi $3 \mathrm{G}$ dapat memudahkan untuk melakukan hal-hal yang buruk seperti mengakses gambar porno, video porno dan hal-hal lain yang berbau pornografi. Pengusaha warnetpun merasa dirugikan karna banyak yang lebih memilih bermain internet dengan alat tersebut dibandingkan dengan harus pergi ke warnet untuk bermain internet.

\section{SIMPULAN}

Berdasarkan hasil penelitian yang dilakukan pada tanggal $30 \mathrm{Mei}$ - 1 Juni dan 911 Juli 2018 di SMP Negeri 9 Pekanbaru untuk akses video pornografi didapatkan hasil kuesioner yang terkumpul sebanyak 258 responden serta dapat disimpulkan bahwa nilai tengah usia responden adalah 13 tahun. Berdasarkan jenis kelamin pada penelitian ini mayoritas adalah laki-laki. Alat yang digunakan untuk akses video pornografi sebagian besar menggunakan smartphone dengan durasi akses video pornografi dengan nilai tengah yaitu 5 menit/akses. Lokasi saat askes video pornografi mayoritas remaja memilih di rumah dengan frekuensi nilai tengah yaitu 5 kali/bulan.

\section{DAFTAR PUSTAKA}

Anisah, N. (2016). Efek Tayangan Pornografi di Internet Pada Perilaku Remaja di Desa Suka Maju Kecamatan Tenggarong Seberang. E-Journal, 4(1), 115-124. Diperoleh dari http://scholar.unand.ac.id

Asti, B. M. (2011). Gurita pornografi membelit remaja. Jawa Tengah: Oase Qalbu.

Djubaedah, N. (2009). Pornografi dan pornoaksi di tinjau dari hukum islam. Jakarta: Kencana.

Dursa, E. (2017). Pengaruh Media Internet Terhadap Perilaku Menyimpang Remaja Di Sekolah Menengah Atas Negeri 1Maros. Fakultas Dakwah dan Komunikasi. UIN Alauddin: Makasar. 
Diperoleh dari http://repositori.uinalauddin.ac.id

KOMINFO (2014). Riset Kominfo dan Unicef mengenai perilku anak dan remaja dalam menggunakan Internet. Di peroleh dari https://www.kominfo.go.id

KPAI (2015). Ribuan anak Indonesia jadi korban Pornografi Internet. Diperoleh dari http://www.kpai.go.id

Muflih, M., Hamzah, H., dan Puniawan, W. A. (2017). Penggunaan Smartphone dan Interaksi Sosial pada Remaja di SMA Negeri 1 Kalasan Sleman Yogyakarta. Idea Nursing Journal, 3(1), 2580-2445. Diperoleh dari https://jurnal.unisyiah. ac.id

Nadesul, H. (2011). Menyayangi Otak. Jakarta: Kompas Media Nusantara.

Potter \& Perry. 2009. Fundamental Keperawatan. Edisi 7. Jakarta: Selemba Medika

Rumyeni, Evawani, E. L., \& Nova, Y. (2013). Pengaruh Terpaan Pornografi Di Media Massa Terhadap Perilaku Remaja Di Kota Pekanbaru. Ilmu Komunikasi. Universitas Riau: Pekanbaru. Diperoleh dari. https://repository.unri.ac.id

Santrock, J. W. (2007). Remaja. Jakarta: Erlangga.

Saputri, O. E. (2014). Gambaran Penggunaan Internet Pada Anak Remaja Di Smp Muhammadiyah 1 Kartasura. Ilmu Keperawatan. Universitas Muhammdiyah: Surakarta. Diperoleh dari http://eprints.ums.ac.id

Sarwono, S. W. (2012). Psikologi remaja. Edisi kelima balas. Jakarta: Rajawali Press.

Stoppard, M. (2010). Panduan kesehatan keluarga. Jakarta: Erlangga.

Suwuh, F., Sefti. R., \& Vandri. K. (2017). Hubungan penggunaan smarthphone dengan perilaku seksual remaja di SMA Negeri 2 Lowongan Kecamatan Lowongan Utara. Fakultas Kedokteran. Universitas Sam Ratulangi: Langowan. Diperoleh dari. https://ejournal.unsrat.ac. id

Willis, S. S. (2012). Remaja \& masalahnya. Bandung: Alfabeta.
Yutifa, H., Ari. P. D., \& Misrawati. (2015). Hubungan Paparan Pornografi melalui Elektronik Terhadap Perilaku Seksual Remaja. Jurnal Ilmu Keperawatan, 2(2), 1141-1148. Diperoleh dari https://media. neliti.com 